\title{
Endoscopic resection with adjuvant treatment versus esophagectomy for early-stage esophageal cancer
}

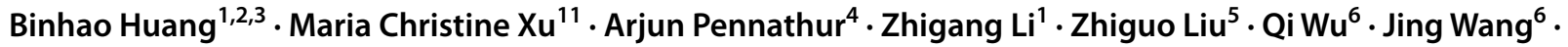

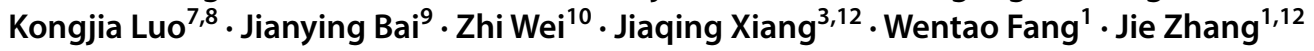

Received: 21 December 2020 / Accepted: 18 March 2021 / Published online: 23 April 2021

(C) The Author(s) 2021

\begin{abstract}
Objective To evaluate the outcome following the strategy of endoscopic R0 resection (ER) plus adjuvant treatment (AT) versus esophagectomy for esophageal squamous cell cancer in T1a invading muscularis mucosa (M3)-T1b stage.

Methods We evaluated the outcomes of 46 esophageal squamous cell cancer (ESCC) patients with T1aM3-T1b stage who underwent ER + AT from the Esophageal Cancer Endoscopic Therapy Consortium (ECETC) and compared these outcomes to 92 patients who underwent esophagectomy. Propensity score matching (1:2) was used, with overall survival (OS) and relapse-free survival (RFS) being compared between the two groups.

Results During a median follow-up of 32 months, there were no statistical differences $(P=0.226)$ in OS between the two groups. The 1-, 2-, and 3-year overall survival in the esophagectomy group was $95 \%, 91 \%$, and $84 \%$, respectively. There were no mortalities within three years in the ER + AT group. The RFS between the two groups was also not significantly different $(P=0.938)$. The 1-, 2-, and 3-year RFS of patients in the esophagectomy group was $90 \%, 90 \%$, and $83 \%$, respectively, while it was $97 \%, 94 \%$, and $74 \%$ in the ER + AT group, respectively. The local recurrence rates between the two groups were not significantly different $(P=0.277)$.

Conclusions This first multicenter analysis showed similar outcomes were found regarding OS and RFS between the two groups in T1aM3-T1b stage patients. ER + AT may be considered in high-risk patients or for those who refuse esophagectomy.
\end{abstract}

Keywords Esophageal neoplasms $\cdot$ Endoscopic resection $\cdot$ Chemoradiotherapy $\cdot$ Esophagectomy

Binhao Huang and MariaChristine Xu have contributed equal to the paper.

Wentao Fang

vwtfang@hotmail.com

$\triangle$ Jie Zhang

zhangjie2289@ hotmail.com

Zhiguo Liu

liuzhiguo@fmmu.edu.cn

1 Department of Thoracic Surgery, Shanghai Chest Hospital, Shanghai, China

2 Department of Gastric Surgery, Fudan University Shanghai Cancer Center, Shanghai, China

3 Department of Oncology, Shanghai Medical College, Fudan University, Shanghai, China

4 Department of Cardiothoracic Surgery, University of Pittsburgh Medical Center, Pittsburgh, PA, USA

5 Xijing Hospital of Digestive Disease, The Air Force Medical University, Xian, China
Esophageal carcinoma has become one of the leading causes of cancer death worldwide [1]. In China, it is still ranked

6 Endoscopy Center, Peking University Cancer Hospital, Beijing, China

7 State Key Laboratory of Oncology in South China, Collaborative Innovation Center for Cancer Medicine, Sun Yat-Sen University Cancer Center, Guangzhou, China

8 Guangdong Esophageal Cancer Institute (GECI), Guangzhou, China

9 Department of Gastroenterology. Xinqiao Hospital, Third Military Medical University, Chongqing, China

10 Gastroenterology Department, The 960th Hospital of the PLA, Jinan, China

11 University of Toronto Schools, Toronto, Canada

12 Department of Thoracic Surgery, Fudan University Shanghai Cancer Center, Shanghai, China 
among the top four malignant tumors for its high morbidity and tumor-related mortality across the country [2]. Therefore, detecting esophageal cancer in the early stage and finding an appropriate therapeutic intervention is urgently needed for a better prognosis.

The past decade has witnessed a boom in endoscopy. It has been widely applied in the screening, diagnosis, and therapy of superficial esophageal cancer owing to its minimally invasive approach [3]. Endoscopic resection (ER) is recommended for selected patients with low-risk characteristics who have early-stage cancer without evidence of lymph node metastasis. For tumors within lamina propria (T1am1-m2), endoscopic R0 resection is believed to be sufficient for a good prognosis [4]. However, the risk of lymph node metastasis increases rapidly when tumors invade muscularis mucosae (T1am3, 9\%), and the risks are even higher when invading beyond submucosa $(16 \%$, $38 \%$, and $64 \%$ for $\mathrm{T} 1 \mathrm{bsm} 1, \mathrm{sm} 2$, and $\mathrm{sm} 3$, respectively) [5]. So, ER alone is considered controversial as a curative treatment for these patients.

A Japanese clinical trial (JCOG9708) found that patients with $\mathrm{T} 1$ esophageal squamous cell carcinoma (ESCC) who underwent definitive chemoradiotherapy would have a comparable survival rate to those after surgery [6]. Potential metastatic lymph nodes could be covered by chemoradiation, but the local recurrence rate was a significant problem because the primary lesion was not removed by chemoradiotherapy [7]. Furthermore, invasion depth could not be precisely evaluated even though endoscopic ultrasonography (EUS) was scheduled before therapy [8]. In other words, some patients might have undergone overtreatment or undertreatment. It was believed that ER provided a more accurate depth of invasion information than EUS $[9,10]$. Therefore, definite chemoradiotherapy without ER is insufficient for these patients either.

Esophagectomy has been considered a standard treatment for those with a high risk of lymph node metastasis. Compared to traditional surgeries like esophagectomy, ER has the advantages of fewer postoperative complications and decreased mortality $[11,12]$. However, lymphadenectomy is not performed during the ER procedure. Hence, some investigators have suggested the addition of chemoradiotherapy to ER (ER + AT) instead of an esophagectomy [13-17] to address the potential lymph node metastasis, with the hope that this strategy can benefit from the combined advantages of ER + AT while ameliorating their shortcomings. Until now, only small single-arm and single-center studies exist [18], and no studies have focused on evaluating this strategy in $\mathrm{T} 1 \mathrm{am} 3-\mathrm{T} 1 \mathrm{~b}$ stage esophageal cancer.

This first multicenter study was conducted to evaluate the outcomes following the strategy of ER + AT for esophageal cancer in the T1aM3-T1b stage versus esophagectomy. This study was based on data from the Esophageal Cancer Endoscopic Therapy Consortium (ECETC).

\section{Methods}

\section{Data collection}

The multicenter data were collected from the ECETC, which consisted of information from 9 independent hospitals including the University of Pittsburgh Medical Center, Shanghai Chest Hospital, Fudan University Shanghai Cancer Center, Xijing Hospital of Digestive Disease, Peking University Cancer Hospital, Sun Yat-Sen University Cancer Center, Xinqiao Hospital, The 960th Hospital of the PLA, and Wuhan General Hospital of the Guangzhou Military. Patient data between September 2011 and February 2017 were collected. The inclusion criteria for patient data were as follows: (1) $\mathrm{cN} 0$ and cM0, (2) endoscopic R0 resection, (3) pathologically diagnosed as T1aM3-T1b esophageal squamous cell cancer, and (4) treated with additional chemotherapy or/and radiotherapy after endoscopic resection. Forty-six patients with esophageal cancer in early stages were included in this study as the $\mathrm{ER}+\mathrm{AT}$ group. Patients who underwent esophagectomy from the main center were chosen as the control group for the comparison. All patients provided written informed consent before treatment. They were also informed that the data would be for research use and might be published after de-identification. This study was approved by the Committee for Ethical Review of Research (Review Board No. 090977-1).

\section{ER techniques}

Endoscopic resection of ECETC included endoscopic multiband mucosectomy (EMBM) and endoscopic submucosal dissection (ESD). EMBM was performed using the Duette Multiband Mucosectomy Kit (DT-6, Cook Medical, Bloomington, IN, USA). The T-knife, dual knife, or VS knife (Erbe Elektromedizin, GmbH, Tübingen, Germany) was used for ESD, under the ENDO CUT IQ model (Erbe platform system). We recommend endoscopic surveillance at 1, 3, 6, 12, 18 , and 24 months within the first 2 years, after curative ER for superficial esophageal cancer.

\section{Chemo/radiotherapy}

The patients who underwent ER received postoperative treatment. The treatments were determined after discussion between doctors and patients. ER patients were not offered esophagectomy in these conditions: (1) patients performance status did not allow the surgery; (2) patients strongly desired organ preservation; (3) patients were likely to develop postoperative complications; (4) presence of other relevant social 
factors, such as a lack of insurance to cover esophagectomy. The primary and standard plan of the chemotherapy regimen involved intravenous infusion of cisplatin $\left(70 \mathrm{mg} / \mathrm{m}^{2} /\right.$ day) on days 1 and 5 -fluorouracil (5-FU) $\left(700 \mathrm{mg} / \mathrm{m}^{2} /\right.$ day for $24 \mathrm{~h}$ ) on days 1 to 5 , every 4 weeks. A total dose of $61.2 \mathrm{~Gy}$ radiation in 34 fractions ( 5 days per week at $1.8 \mathrm{~Gy} /$ day) was applied. The clinical target volume included the pre-therapeutic extension of the primary tumor and regional lymph nodes with some modification in different centers. Reginal nodes involved in radiation are based on tumor location. Supra-clavicular, upper mediastinal, and subcarinal nodal areas are for the upper thoracic esophagus; mediastinal and perigastric nodal areas are for the middle thoracic esophagus; and mediastinal, perigastric, and celiac nodal areas are for the lower thoracic esophagus.

\section{Definitive surgery}

Esophagectomy and lymphadenectomy were performed in the main center, and the surgical procedure was determined based on the feature of the lesion and the experience of the primary surgeon. The surgery was conducted by Ivor Lewis and three-incision/McKeown operative approach. Patients had a follow-up visit in the clinic after esophagectomy every 3 months in the first year, every 4-6 months in the second year, and annually thereafter. For the esophagectomy group, yearly endoscopic surveillance was recommended. Patients would receive additional endoscopic examination if they had dysphagia. Computed tomography (CT) imaging was performed every 3 months within the first 2 years, and every half year afterward.

\section{Pathological diagnosis and staging}

Tumor location was determined by a report of endoscopy before surgery. Tumor stages were reassessed based on the 2017 International Union Against Cancer (UICC) and the American Joint Committee on Cancer (AJCC) 8th version TNM classification system. The depth of invasion, surgical margin, and lymphovascular invasion (LVI) were examined and determined by at least two independent pathologists who were blinded to clinical information.

\section{Propensity score matching (PSM)}

Propensity score matching $[19,20]$ was performed with 1:2 nearest-neighbor matching without replacement to identify matched cohorts for the two treatment modalities (ER + AT and esophagectomy only). This method was adopted to balance the covariates, which could have influenced the survival outcomes between the two groups.
In the ECETC set, we included gender, age, location, depth of invasion, and LVI for matching. Based on this set of covariates, the propensity score was estimated using logistic regression. Standardized mean differences (SMD) were used to assess the balance of baseline data [21]. The statistical analyses were conducted using $\mathrm{R}$ version 3.3.1 software (R, CA, USA).

\section{Statistical analysis}

The number and percentage of patients for each subgroup were listed unless otherwise specified. Local recurrence included the recurrence at the primary site, mediastinal lymph nodes and a metachronous lesion. Pearson's $\chi^{2}$ test or Fisher's exact test was used for comparing frequencies for categorical variables, and one-way analysis of variance (ANOVA) or Student's $t$-test was used for continuity variables. Kaplan-Meier curve and the log-rank test were used to evaluate overall survival (OS) and relapse-free survival (RFS). Competing risk method was used to evaluate local recurrence rate with death without local recurrence treated as competing risk event. The Cox regression model was used for univariate and multivariate analysis regarding OS and RFS. All statistical analyses were performed in SPSS version 22.0, and figures were generated by Prism version 6.0 and $\mathrm{R}$ version 3.3.1 software (R, CA, USA). A $P$ value of $<0.05$ was considered statistically significant for all analyses.

\section{Results}

\section{Characteristics of the patients before matching}

Data of the patients from the ECETC set before and after PSM are listed in Table 1. After evaluation by pathologists, the patients were all diagnosed with ESCC. Before matching, there were more patients with lower esophageal cancer $(P<0.001, \mathrm{SMD}=0.850)$ and $\mathrm{T1b}(P=0.041$, $\mathrm{SMD}=0.313)$ in the esophagectomy group. According to the pathologic information after esophagectomy, 15\% (47/311) of patients had positive lymph nodes and pathologic upstage. The percentage of upstaging was $4.5 \%$ and $19.7 \%$ for T1a and $\mathrm{T} 1 \mathrm{~b}$ patients, respectively.

\section{Characteristics of the patients after matching}

After matching, all the factors were balanced, and we finally included 46 patients in the ER + AT group with 34 males and 12 females, with an age range of $61.13 \pm 8.10$ years. Overall, $74 \%$ received additional radiotherapy, while $26 \%$ received chemotherapy in the ER + AT group. Regarding tumor stage, 20 patients were $\mathrm{T} 1 \mathrm{am} 3,3$ patients were $\mathrm{T} 1 \mathrm{bsm} 1$, and 17 were $\geq \mathrm{T} 1 \mathrm{bsm} 2$. It is not routine for all centers to distinguish 
Table 1 Distribution of variables between ER + AT and esophagectomy groups before and after propensity score matching in the ECETC Set

\begin{tabular}{|c|c|c|c|c|c|c|c|c|}
\hline & \multicolumn{2}{|c|}{ Before matching } & \multirow[t]{3}{*}{$P$ value } & \multirow[t]{3}{*}{ SMD (95\%CI) } & \multicolumn{2}{|c|}{ After matching } & \multirow[t]{3}{*}{$P$ value } & \multirow[t]{3}{*}{ SMD (95\%CI) } \\
\hline & $\mathrm{ER}+\mathrm{AT}$ & Esophagectomy & & & $\mathrm{ER}+\mathrm{AT}$ & Esophagectomy & & \\
\hline & $N=46$ & $N=311$ & & & $N=46$ & $N=92$ & & \\
\hline Gender & & & 0.771 & $\begin{array}{l}0.045(-0.264 \text { to } \\
0.355)\end{array}$ & & & 0.672 & $\begin{array}{l}0.076(-0.278 \text { to } \\
0.430)\end{array}$ \\
\hline Male & $34(73.91 \%)$ & $236(75.88 \%)$ & & & $34(73.91 \%)$ & $71(77.17 \%)$ & & \\
\hline Female & $12(26.09 \%)$ & $75(24.12 \%)$ & & & $12(26.09 \%)$ & $21(22.83 \%)$ & & \\
\hline Age, years $(\bar{x} \pm s)$ & $61.13 \pm 8.10$ & $60.84 \pm 7.78$ & 0.811 & $\begin{array}{l}0.165(-0.145 \text { to } \\
0.474)\end{array}$ & $61.13 \pm 8.10$ & $61.07 \pm 6.72$ & 0.960 & $\begin{array}{l}0.009(-0.345 \text { to } \\
0.363)\end{array}$ \\
\hline Position & & & $<0.001^{*}$ & $0.850(0.534-1.166)$ & & & 0.739 & $\begin{array}{l}0.128(-0.226 \text { to } \\
0.482)\end{array}$ \\
\hline Upper & $13(28.26 \%)$ & $30(9.65 \%)$ & & & $13(28.26 \%)$ & $21(22.83 \%)$ & & \\
\hline Middle & $27(58.70 \%)$ & $135(43.41 \%)$ & & & $27(58.70 \%)$ & $60(65.22 \%)$ & & \\
\hline Lower & $6(13.04 \%)$ & $146(46.95 \%)$ & & & $6(13.04 \%)$ & $11(11.96 \%)$ & & \\
\hline Stage & & & $0.041^{*}$ & $0.313(0.003-0.624)$ & & & 0.386 & $\begin{array}{l}0.156(-0.198 \text { to } \\
0.510)\end{array}$ \\
\hline T1a & $20(43.48 \%)$ & $89(28.62 \%)$ & & & $20(43.48 \%)$ & $33(35.87 \%)$ & & \\
\hline $\mathrm{T} 1 \mathrm{~b}$ & $26(56.52 \%)$ & $222(71.38 \%)$ & & & $26(56.52 \%)$ & $59(64.13 \%)$ & & \\
\hline LVI & & & 0.659 & $\begin{array}{l}0.109(-0.201 \text { to } \\
0.418)\end{array}$ & & & 1.000 & $\begin{array}{l}0.036(-0.318 \text { to } \\
0.390)\end{array}$ \\
\hline Negative & $41(89.13 \%)$ & $287(92.28 \%)$ & & & $41(89.13 \%)$ & $83(90.22 \%)$ & & \\
\hline Positive & $5(10.87 \%)$ & $24(7.72 \%)$ & & & $5(10.87 \%)$ & $9(9.78 \%)$ & & \\
\hline
\end{tabular}

Data presented as $N(\%)$ unless otherwise specified

ECETC esophageal cancer endoscopic therapy consortium, ER endoscopic resection, $A T$ adjuvant therapy, SMD standardized mean difference $P$ value was derived from $\chi^{2}$ test or Fisher's exact test for categorical variables, and ANOVA for continuous variables

between sm1, sm2, and sm3 within T1b tumors. Another 6 tumors that invaded submucosa were classified into T1bsmx.

There were 92 patients in the esophagectomy group with 71 males and 21 females, with an age range of $61.07 \pm 6.72$ years. No difference was found in gender, age, location, $\mathrm{T}$ stage, and LVI between the two groups $(P>0.05, \mathrm{SMD}<0.200)$. The ER + AT group had a longer tumor length (median, $4 \mathrm{~cm}$ vs $2 \mathrm{~cm} ; P<0.001$ ) compared to esophagectomy. We did not include this for PSM because patients could not be fully matched. Instead, we performed multivariate analysis, including tumor length as a covariate. After matching, the percentage of lymph node upstaging was $9.8 \%(9 / 92)$.

\section{Comparison of overall survival}

There were no statistical differences (HR 2.43 with 95\%CI 0.78 to $7.56, P=0.226$ ) in OS between the two groups (Fig. 1A). After a median follow-up of 38 months, one-, two-, and three-year OS in the esophagectomy group was $95 \%, 91 \%$, and $84 \%$, respectively. Specifically, there were 10 cancer-specific deaths in the esophagectomy group, and 2 perioperative deaths and 1 non-tumor death were excluded from this number. There were no mortalities within 3 years in the ER + AT group, with a median follow-up of 30 months. There were 2 cancer-specific deaths in the ER + AT group after 3 years.

\section{Comparison of relapse-free survival and local recurrence rate}

The RFS between the two groups was not significantly different (HR $=1.04,95 \%$ CI 0.41 to $2.60, P=0.938$ ) (Fig. 1B). The 1-, 2-, and 3-year RFS rate of patients in the esophagectomy group was $90 \%, 90 \%$, and $83 \%$, respectively, while it was $97 \%, 94 \%$, and $74 \%$ in the ER + AT group, respectively. Local recurrence included the recurrence at the primary site, mediastinal lymph nodes and a metachronous lesion. The local recurrence rates between the two groups were not significantly different (HR 0.50, 95\% CI 0.12 to $2.11, P=0.277$ ) (Supplementary Fig. 1).

In ER + AT group, there was no difference in overall survival (Supplementary Fig. 2A), relapse-free survival (Supplementary Fig. 2B) or local recurrence rate (Supplementary Fig. 2C) between those who received chemotherapy and radiation $(P=0.053,0.300$ and 0.501 , respectively). 


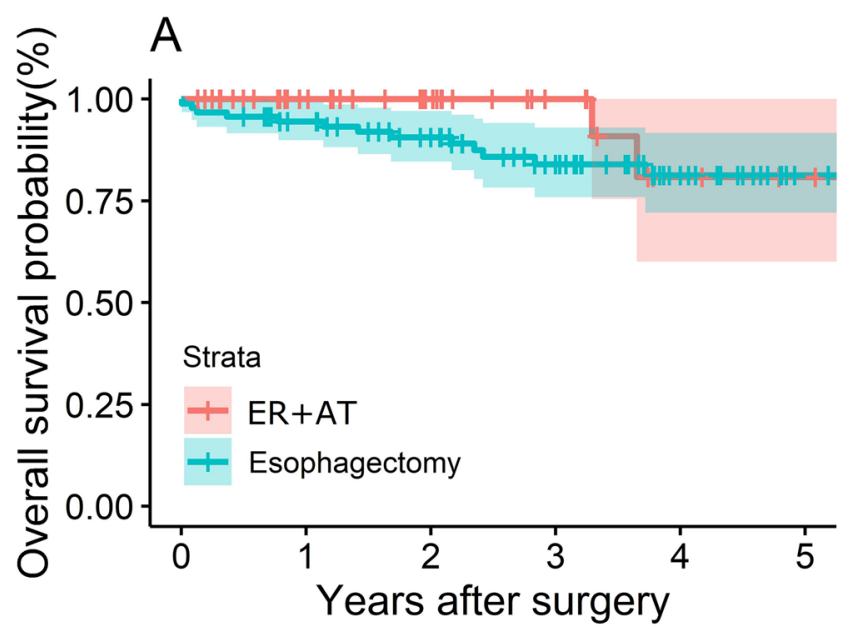

Fig. 1 Survival analysis by different therapeutic strategy in the ECETC set. A KM curves for overall survival with abstracted number at risk displayed (HR 2.43 with $95 \%$ CI 0.78 to $7.56, P=0.226$ ).

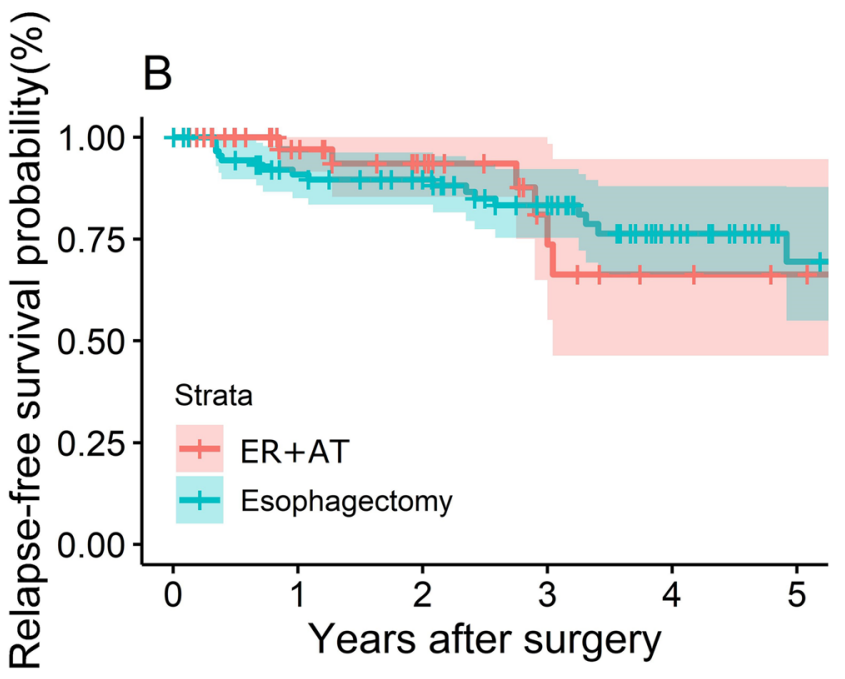

B KM curves for relapse-free survival with abstracted number at risk displayed (HR $1.04,95 \%$ CI 0.41 to $2.60, P=0.938$ )
Table 2 Cox regression model for comparison between $\mathrm{ER}+\mathrm{AT}$ and esophagectomy

\begin{tabular}{lllllll}
\hline ER + AT vs Esophagectomy & Overall survival & & & \multicolumn{2}{l}{ Relapse-free survival } \\
\cline { 2 - 3 } & Hazard ratio (95\% CI) & $P$ value & & Hazard ratio (95\% CI) & $P$ value \\
\hline Univariate model & $0.409(0.092-1.822)$ & 0.241 & & $0.964(0.380-2.446)$ & 0.938 \\
Multivariate model & $0.299(0.056-1.596)$ & 0.158 & & $1.272(0.404-4.005)$ & 0.681 \\
\hline
\end{tabular}

Multivariate model: Including gender, age, tumor location, tumor length, stage and LVI as covariates ECETC esophageal cancer endoscopic therapy consortium, ER endoscopic resection, $A T$ adjuvant therapy

\section{Further analysis in Cox regression models}

To strengthen our findings, we also conducted univariate and multivariate analysis using Cox regression models and included those factors which may influence prognosis. Table 2 presents the results of the comparisons OS and RFS between the study groups. Compared to esophagectomy, $\mathrm{ER}+\mathrm{AT}$ had a similar OS $(P=0.241)$ and RFS $(P=0.938)$ in the univariate model. A further multivariate analysis that included all the clinicopathologic information validated the similarity of OS $(P=0.158)$ and RFS $(P=0.681)$ between $\mathrm{ER}+\mathrm{AT}$ and esophagectomy. A sensitivity analysis using the before matching cohort to conduct multivariable regression model also found comparable OS $(P=0.180)$ and RFS $(P=0.884)$ (Table 3).

\section{Discussion}

Endoscopic resection alone might not be enough for patients with T1am3-T1b esophageal cancer mainly due to inadequate resection and unremoved positive lymph nodes, which are significantly related to more reduced survival.
Table 3 Multivariable Cox regression model for comparison between $\mathrm{ER}+\mathrm{AT}$ and esophagectomy using the before matching cohort

\begin{tabular}{lllll}
\hline Overall survival & & & \multicolumn{2}{l}{ Relapse-free survival } \\
\cline { 1 - 1 } \cline { 1 - 1 } Hazard ratio (95\% CI) & $P$ value & & Hazard ratio (95\% CI) & $P$ value \\
\hline $0.373(0.088-1.587)$ & 0.180 & & $0.934(0.386-2.273)$ & 0.884 \\
\hline
\end{tabular}

The adjusted covariates include gender, age, tumor location, tumor length, stage and LVI

Our preliminary data also demonstrated $\mathrm{Tm} 3 / \mathrm{sm} 1$ patient who underwent endoscopic resection alone had worse survival compared with esophagectomy. Therefore, investigators have been trying for years to find the risk factors that can predict lymph node metastasis [22-25], and those were found to predict high risk are recommended for an indication of esophagectomy. A scoring system based on the National Cancer Database indicated that layer of invasion, tumor size, differentiation, and lymphovascular invasion (LVI) were associated with positive lymph nodes [22]. Sgourakis et al. concluded that the best predictors were sm3 invasion and presence of LVI [26], while Cen et al. also demonstrated that LVI was an independent risk factor 
for predicting lymph node metastasis [27]. Furthermore, our previous study revealed that LVI had a solid predictive function of lymph node status in multivariate analysis [28]. So, in addition to routine clinicopathologic factors, we also included LVI as one of the variables for PSM.

Here, we introduce an "all-covered mode" as ER + AT strategy, and it can be applied for T1am3-T1b stage esophageal cancer. It was reported as an effective and safe approach in single-center study, and it improved the local control rate $[15,16]$.The rationale of ER plus adjuvant therapy is that ER can obtain accurate $\mathrm{T}$ staging while the primary lesion is removed, and adjuvant therapy can further reduce the potential of both local and mediastinal lymph node recurrence. Moreover, the combination approach preserves the function of the esophagus, which significantly improves the quality of life. Up to now, this is the first multicenter analysis, comparing endoscopic resection with adjuvant treatment versus esophagectomy for early-stage esophageal cancer. Some literatures showed that squamous cell carcinoma of proximal esophagus equivalent survival with CRT vs surgery [29], even in later stages. Kato et al. reported the $87.5 \%$ (63 of 72) CR rate of definitive CRT for clinical stage I ESCC, and achieved comparable survival rate to those receiving surgery [6]. Here, we introduced ER before chemo/radiotherapy to obtain an accurate $\mathrm{T}$ stage information. Additionally, $\mathrm{ER}+\mathrm{AT}$ can be applied to middle and distal esophagus cancer too.

In our study, we analyzed the outcomes of ESCC treated with ER and AT from the ECETC, which included 9 hospitals and compared the findings to patients who underwent esophagectomy. We did not find significant differences in OS, RFS, and local recurrence rates between the two groups, despite a tendency of a higher local recurrence rate in the ER + AT group. The results of local recurrence were almost consistent with Nelson's conclusion, which found that esophageal preservation was associated with an increased risk of local recurrence [30]. However, additional therapy was not applied in Nelson's study. Given that no local recurrence occurred within 2 years in the $\mathrm{ER}+\mathrm{AT}$ group, it is reasonable to confirm the effectiveness of subsequent AT. Here, we observed a rising local recurrence rate after 3 years. We assumed this result was mainly due to the following 2 reasons. First, for ER + AT patients, adjuvant therapy could effectively reduce the risk of recurrence and prolong the time to disease progression. Therefore, there was no local recurrence cases in first 3 years after treatment. However, the regional lymph nodes were not resected for these patients, thus became a potential risk factor for some local recurrent cases. Second, metachronous lesion in the later is another explanation, which was caused by preserved esophagus during ER. So we recommended regular follow-up for a long time. In addition, it is also important to educate the patients to quit smoking, limit alcohol to avoid cancer recurrence.

Treatment decision-making for patients with multiple medical problems has always been difficult. In addition to obtaining a better long-term survival, for some patients, advanced age or comorbidities also need to be taken into account $[31,32]$. To make the best choice for patients, we need to balance the benefits and risks. ER plus adjuvant therapy is an alternative choice for those patients who are at high risk and are not operative candidates.

The present study had some limitations. First, although the data were collected prospectively from an institutional database, selection bias was unavoidable, as it was a retrospective analysis. PSM was performed to normalize the variables between the two groups to reduce bias. However, unmeasured confounders like patient comorbidity before treatment were not included in this study. Generally, serious comorbidity would be a reason to reject esophagectomy. Considering that more ER + AT patients may have preoperative comorbidity, and relatively better outcomes would have been found if we had matched it, it was acceptable to obtain a similar prognosis without these data. Second, additional therapy to endoscopic resection was not uniform among the different centers. If LVI is positive, patients are more likely to have CT. If the patients are $\mathrm{T} 1 \mathrm{~b} \mathrm{sm} 2$ or sm3, they are more likely to have RT. Additionally, different centers also have their preference for treatment modalities. There is no consensus or guideline for additional treatment, and not all patients in the esophagectomy group underwent initial ER. Heterogeneity of the staging procedure prior to treatment also existed, because it is difficult to standardize procedures across institutions. Third, this study examined patients who had squamous cell carcinoma, and further studies are required to evaluate outcomes in esophageal adenocarcinoma. Finally, the follow-up time was not sufficiently long in this study. Further prospective studies with a cohort of patients and longer follow-up are required to evaluate the strategy of endoscopic resection followed by additional chemoradiotherapy for the treatment of esophageal cancer in T1aM3-T1b stage.

In conclusion, we compared the outcomes of chemoradiotherapy following endoscopic R0 resection for esophageal cancer in the T1aM3-T1b stage versus esophagectomy. Comparable OS, RFS, and local recurrence rates were found between the two groups. The ER plus adjuvant therapy strategy may be considered in ESCC patients who have multiple high-risk factors or those who refuse esophagectomy.

Supplementary Information The online version contains supplementary material available at https://doi.org/10.1007/s00464-021-08466-2.

Acknowledgements This work is supported, in part, Key projects of traditional Chinese medicine research project of Shanghai Health 
Committee (2020LZ004), Talent plan of Technology transfer from Shanghai Municipal Education Commission.

Funding Information Key project of Chinese Medicine Research Project of Shanghai Health Department (2020LZ0046000) and ShanghaiMunicipal Education Department "Shanghai University Teachers' Innovation and Research" Talent Program.

\section{Declarations}

Disclosures Binhao Huang, Maria Christine Xu, Arjun Pennathur, James D Luketich, Zhigang Li, Zhiguo Liu, Qi Wu, Jing Wang, Kongjia Luo, Jianying Bai, Zhi Wei, Jiaqing Xiang, Wentao Fang and Jie Zhang have no conflicts of interest or financial ties to disclose.

Open Access This article is licensed under a Creative Commons Attribution 4.0 International License, which permits use, sharing, adaptation, distribution and reproduction in any medium or format, as long as you give appropriate credit to the original author(s) and the source, provide a link to the Creative Commons licence, and indicate if changes were made. The images or other third party material in this article are included in the article's Creative Commons licence, unless indicated otherwise in a credit line to the material. If material is not included in the article's Creative Commons licence and your intended use is not permitted by statutory regulation or exceeds the permitted use, you will need to obtain permission directly from the copyright holder. To view a copy of this licence, visit http://creativecommons.org/licenses/by/4.0/.

\section{References}

1. Siegel RL, Miller KD, Jemal A (2019) Cancer statistics, 2019. CA Cancer J Clin 69:7-34

2. Chen W, Zheng R, Baade PD, Zhang S, Zeng H, Bray F, Jemal A, $\mathrm{Yu}$ XQ, He J (2016) Cancer statistics in China, 2015. CA Cancer $\mathrm{J}$ Clin 66:115-132

3. di Pietro M, Canto MI, Fitzgerald RC (2018) Endoscopic management of early adenocarcinoma and squamous cell carcinoma of the esophagus: screening, diagnosis, and therapy. Gastroenterology $154: 421-436$

4. Oyama T, Tomori A, Hotta K, Morita S, Kominato K, Tanaka M, Miyata Y (2005) Endoscopic submucosal dissection of early esophageal cancer. Clin Gastroenterol Hepatol 3:S67-S70

5. Akutsu Y, Uesato M, Shuto K, Kono T, Hoshino I, Horibe D, Sazuka T, Takeshita N, Maruyama T, Isozaki Y, Akanuma N, Matsubara H (2013) The overall prevalence of metastasis in T1 esophageal squamous cell carcinoma: a retrospective analysis of 295 patients. Ann Surg 257:1032-1038

6. Kato H, Sato A, Fukuda H, Kagami Y, Udagawa H, Togo A, Ando N, Tanaka O, Shinoda M, Yamana H, Ishikura S (2009) A phase II trial of chemoradiotherapy for stage I esophageal squamous cell carcinoma: Japan Clinical Oncology Group Study (JCOG9708). Jpn J Clin Oncol 39:638-643

7. Yamamoto S, Ishihara R, Motoori M, Kawaguchi Y, Uedo N, Takeuchi Y, Higashino K, Yano M, Nakamura S, Iishi H (2011) Comparison between definitive chemoradiotherapy and esophagectomy in patients with clinical stage I esophageal squamous cell carcinoma. Am J Gastroenterol 106:1048-1054
8. Bergeron EJ, Lin J, Chang AC, Orringer MB, Reddy RM (2014) Endoscopic ultrasound is inadequate to determine which T1/T2 esophageal tumors are candidates for endoluminal therapies. J Thorac Cardiovasc Surg 147:765-771

9. Ajani JA, Barthel JS, Bentrem DJ (2011) Esophageal and esophagogastric junction cancers v2.2018, NCCN Clinical Practice Guidelines in Oncology. J Natl Compr Cancer Netw 17:855

10. Thosani N, Singh H, Kapadia A, Ochi N, Lee JH, Ajani J, Swisher SG, Hofstetter WL, Guha S, Bhutani MS (2012) Diagnostic accuracy of EUS in differentiating mucosal versus submucosal invasion of superficial esophageal cancers: a systematic review and meta-analysis. Gastrointest Endosc 75:242-253

11. Pech O, Bollschweiler E, Manner H, Leers J, Ell C, Holscher AH (2011) Comparison between endoscopic and surgical resection of mucosal esophageal adenocarcinoma in Barrett's esophagus at two high-volume centers. Ann Surg 254:67-72

12. Dunbar KB, Spechler SJ (2012) The risk of lymph-node metastases in patients with high-grade dysplasia or intramucosal carcinoma in Barrett's esophagus: a systematic review. Am J Gastroenterol 107(850-862):863

13. Kurokawa Y, Muto M, Minashi K, Boku N, Fukuda H (2009) A phase II trial of combined treatment of endoscopic mucosal resection and chemoradiotherapy for clinical stage I esophageal carcinoma: Japan Clinical Oncology Group Study JCOG0508. Jpn J Clin Oncol 39:686-689

14. Shimizu Y, Kato M, Yamamoto J, Nakagawa S, Tsukagoshi H, Fujita M, Hosokawa M, Asaka M (2004) EMR combined with chemoradiotherapy: a novel treatment for superficial esophageal squamous-cell carcinoma. Gastrointest Endosc 59:199-204

15. Kawaguchi G, Sasamoto R, Abe E, Ohta A, Sato H, Tanaka K, Maruyama K, Kaizu M, Ayukawa F, Yamana N, Liu J, Takeuchi M, Kobayashi M, Aoyama H (2015) The effectiveness of endoscopic submucosal dissection followed by chemoradiotherapy for superficial esophageal cancer. Radiat Oncol 10:31

16. Hisano O, Nonoshita T, Hirata H, Sasaki T, Watanabe H, Wakiyama H, Ono M, Ohga S, Honda H (2018) Additional radiotherapy following endoscopic submucosal dissection for T1a-MM/T1bSM esophageal squamous cell carcinoma improves locoregional control. Radiat Oncol 13:14

17. Kam TY, Kountouri M, Roth A, Frossard JL, Huber O, Monig S, Zilli T (2018) Endoscopic resection with adjuvant chemo-radiotherapy for superficial esophageal squamous cell carcinoma: a critical review. Crit Rev Oncol Hematol 124:61-65

18. Goense L, Meziani J, Borggreve AS, van Rossum PS, Meijer GJ, Ruurda JP, van Hillegersberg R, Weusten BL (2018) Role of adjuvant chemoradiotherapy after endoscopic treatment of early-stage esophageal cancer: a systematic review. Miner Chir 73:428-436

19. Adamina M, Guller U, Weber WP, Oertli D (2006) Propensity scores and the surgeon. Br J Surg 93:389-394

20. Austin PC (2007) Propensity-score matching in the cardiovascular surgery literature from 2004 to 2006: a systematic review and suggestions for improvement. J Thorac Cardiovasc Surg 134:1128-1135

21. McMurry TL, Hu Y, Blackstone EH, Kozower BD (2015) Propensity scores: methods, considerations, and applications in the journal of thoracic and cardiovascular surgery. J Thorac Cardiovasc Surg 150:14-19

22. Weksler B, Kennedy KF, Sullivan JL (2017) Using the National Cancer Database to create a scoring system that identifies patients with early-stage esophageal cancer at risk for nodal metastases. J Thorac Cardiovasc Surg 154:1787-1793

23. Davison JM, Landau MS, Luketich JD, McGrath KM, Foxwell TJ, Landsittel DP, Gibson MK, Nason KS (2016) A model based on pathologic features of superficial esophageal adenocarcinoma complements clinical node staging in determining risk of metastasis to lymph nodes. Clin Gastroenterol Hepatol 14:369-377 
24. Leers JM, DeMeester SR, Oezcelik A, Klipfel N, Ayazi S, Abate E, Zehetner J, Lipham JC, Chan L, Hagen JA, DeMeester TR (2011) The prevalence of lymph node metastases in patients with $\mathrm{T} 1$ esophageal adenocarcinoma a retrospective review of esophagectomy specimens. Ann Surg 253:271-278

25. Ikawa T, Ishihara R, Konishi K, Morimoto M, Hirata T, Kanayama N, Yamamoto S, Matsuura N, Wada K, Hayashi K, Ogawa K, Teshima T (2019) Failure patterns after adjuvant chemoradiotherapy following endoscopic resection for superficial esophageal squamous cell carcinoma. Cancer Med 8:4547-4554

26. Sgourakis G, Gockel I, Lang H (2013) Endoscopic and surgical resection of $\mathrm{T} 1 \mathrm{a} / \mathrm{T} 1 \mathrm{~b}$ esophageal neoplasms: a systematic review. World J Gastroenterol 19:1424-1437

27. Cen P, Hofstetter WL, Lee JH, Ross WA, Wu TT, Swisher SG, Davila M, Rashid A, Correa AM, Ajani JA (2008) Value of endoscopic ultrasound staging in conjunction with the evaluation of lymphovascular invasion in identifying low-risk esophageal carcinoma. Cancer 112:503-510

28. Zhuge L, Wang S, Xie J, Huang B, Zheng D, Zheng S, Mao H, Pennathur A, Sanchez MV, Luketich JD, Xiang J, Chen H, Zhang J (2018) A model based on endoscopic morphology of submucosal esophageal squamous cell carcinoma for determining risk of metastasis on lymph nodes. J Thorac Dis 10:6846-6853
29. Deng H, Li G, Luo J, Alai G (2019) Can definitive chemoradiotherapy be an alternative to surgery for early-stage oesophageal cancer? Interact Cardiovasc Thorac Surg 28:37-40

30. Nelson DB, Dhupar R, Katkhuda R, Correa A, Goltsov A, Maru D, Sepesi B, Antonoff MB, Mehran RJ, Rice DC, Vaporciyan AA, Davila M, Davila R, Betancourt S, Ajani J, Hofstetter WL (2018) Outcomes after endoscopic mucosal resection or esophagectomy for submucosal esophageal adenocarcinoma. J Thorac Cardiovasc Surg 156:406-413

31. Choi JY, Park YS, Jung HY, Ahn JY, Kim MY, Lee JH, Choi KS, Kim DH, Choi KD, Song HJ, Lee GH, Cho KJ, Kim JH (2011) Feasibility of endoscopic resection in superficial esophageal squamous carcinoma. Gastrointest Endosc 73:881-889

32. Tang B, Bai JY, Zhao XY, Fan CQ, Yang X, Deng L, Yang SM, Yu J (2015) Endoscopic submucosal dissection for superficial esophageal cancer with near-circumferential lesions: our experience with 40 patients. Surg Endosc 29:2141-2148

Publisher's Note Springer Nature remains neutral with regard to jurisdictional claims in published maps and institutional affiliations. 